\title{
The Human Oral Cancer and Molecular Biology
}

Prasad MSV ${ }^{1}$, J acob Prakash $\mathrm{A}^{2}$, Chalapathi $\mathrm{KV}^{3}$, Suresh $V^{4}$, Subhash AV ${ }^{5}$, Vinay Hiremath ${ }^{6}$

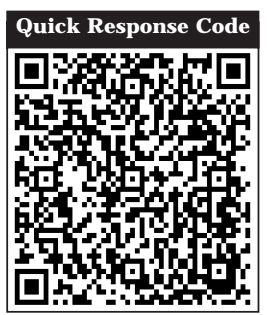

doi: $10.5866 / 2014.631620$

${ }^{1,2 \& 3}$ Assistant professor

${ }^{4,5}$ Reader

${ }^{6}$ Professor \& Head

Department of Oral \& Maxillofacial Pathology

Lenora Institute of Dental Sciences

Rajamundry, Andhra Pradesh.

\section{Article Info:}

Received: April 14, 2014

Review Completed: May 12, 2014

Accepted: J une 10, 2014

Available Online: October, 2014 (www.nacd.in)

(c) NAD, 2014 - All rights reserved

Email for correspondence:

\section{ABSTRACT:}

The molecular biology and its application in the study of cancer have significantly advanced the field of human cancer research. Two classes of highly conserved cellular genes in the malignant transformation process include oncogenes and tumor suppressor genes were demonstrated. This review provides an attempt to assess the current status of the molecular biology of human oral cancer.

Key words: Molecular biology, Oral cancer.

\section{INTRODUCTION:}

The ICD defines oral cancer as cancer of the oral cavity and pharynx. Cancer of the oral cavity includes cancer of the lip, tongue, salivary glands, gum \& floor. Pharyngeal cancer of the mouth includes oropharynx, nasopharynx, hypopharynx and other buccal areas. Oral cancer is the sixth most common cancer for both gender in the general population and the third most common cancer in developing nations. Cancer prevalence in India is estimated to be around 2.5 million, with over $8,00,000$ new cases and 5,50,000 deaths occurring each year due to this disease. Different cancers occur in different states of our country. Oesophageal cancers: Southern states of I ndia likeKarnataka and Tamil Nadu and also in Maharashtra and Gujarat. Stomach cancers: Southern India with the highest incidence in Chennai. Oral cancers: Kerala (South India) Pharyngeal cancers: Mumbai (Western India). Thyroid cancers occur among women: Kerala. Gall bladder cancer: Northern India, particularly in Delhi and West Bengal. ${ }^{1,2}$

Tobacco and alcohol remain the most important risk factors for squamous cell carcinomas of the oral 
cavity. Viruses, most notably the human papillomavirus al so havelong been linked to human oral carcinogenesis. ${ }^{3,4}$

\section{Molecular Basis and Biology of Human Oral Cancer:}

Carcinogenesis is a complex, multi-step process in which genetic events within signal transduction pathways governing normal cellular physiology are quantitatively or qualitatively altered. Therearetwo mechanisms by which proto-oncogenes can be converted to cellular oncogenes: ${ }^{5}$

- Quantitative: Tumour formation induced by increase in the absolute number of protooncogene products or by its production in inappropriate cell types.

- Qualitative: Conversion from proto-oncogene to transforming gene includes changes in the nucleotide sequence and acquisition of the new properties.

Under normal conditions the regulatory pathways controls functions such as cell division, differentiation and adhesion. These signals either directly alter cell function or stimulate the transcription of genes, whose proteins effect the change (signals and cell function are depicted in the picture below). Cell function can be demonstrated by two appropriate terms such as Senescence and Ageing. Senescence refers to a post maturational process that leads to diminished homeostasis and increased vulnerability of organism to death. Ageing in contrast refers to any time related process and is a continuous process that starts at conception and continues until death. ${ }^{6,7}$

Cancer is the result of an accumulation of changes in the excitatory and inhibitory cellular pathways occur at any level of given pathway. Generally 3-6 mutations are needed to transform a normal cell to malignant counterpart. ${ }^{2}$

\section{CYTOGE NETICS OF HUMAN ORAL CANCER:}

In al most two-thirds of all head and neck cancer cells are del eted in the region located in chromosome 9p21-22, suggesting a gene in this region is mutated early in oral carcinogenesis, similarly pl6, 3p and $13 q$ also. ${ }^{8}$

\section{Essential Alterations for Malignant Transformation}

- Self sufficiency of growth signals: Tumors have capacity to proliferate without external stimuli, as a consequence of oncogene activation.

- Insensitivity to growth inhibitory signals: Tumors may not respond to inhibitory molecules such as transforming growth factor (TGF-â), cyclin dependent kinase (CDK) inhibitors

- Evasion of apoptosis: Tumors become resistant to programmed cell death, due to inactivation of p53.

- Defects in DNA Repair: Tumors fail to repair DNA damage, due to loss of function of p53.

- Limitless replicative potential: Tumor cell have unrestricted proliferative capacity $\&$ associated with maintenance of tel omere length $\&$ function.

- Sustained angiogenesis: Genetic abnormalities that dysregulate the growth can lead to sustained angiogenesis. Tumors can't enlarge beyond 1 - $2 \mathrm{~mm}$ in diameter, unless they are vascularized. This vascularization can be induced by various factors: importantly vascular endothelial growth factors (VEGF).

- Ability to invade and metastasis: Biologic hallmark of malignant neoplasm for invasion and metastasis are integrins \& matrix metalloproteins (MMP's). ${ }^{9-11}$

\section{Genetic damage in oral cancer cells can be divided into two categories:-}

1. Dominant changes: Those occur in protooncogenes and certain tumour supressor genes (TSGs) resulting in gain of function.

2. Recessive changes- Those occur in growthinhibitory pathway genes or commonly in tumor suppressor genes causing loss of function. ${ }^{13}$

\section{Oncogenes I mplicated In Human Oral Cancer}

E pidermal growth factor receptor (EGFR)/ c-erb 1, members of the ras family, cmyc, bcl-1, c-erb BI, transforming growth factor-alpha (TGFá). 


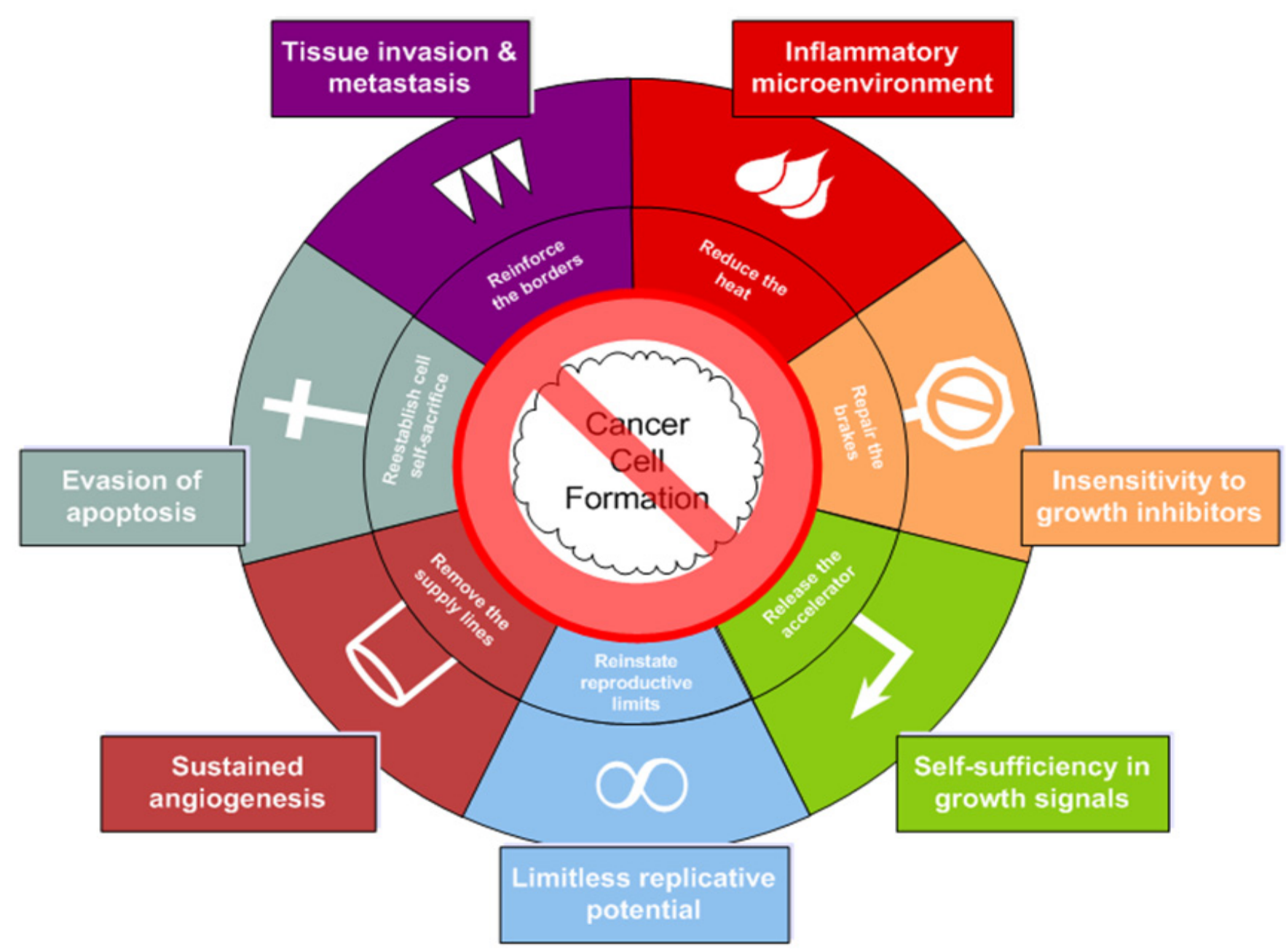

Flow Chart: Depicting Simplified Scheme of Molecular Basis of Cancer

\section{Selected Oncogenes}

Growth Factors: PDGF-â chain, Fibroblast growth factors, TGFá, HGF

Growth Factor Receptors: EGF-receptor family, CSF-1 receptor, Receptor for neurotrophic factors, PDGF receptor, Receptor for stem cell (steel) factor

Proteins I nvolved in Signal Transduction: GTPbinding K-RAS, H-RAS, N-RAS, N onreceptor tyrosine kinase $A B L$, RAS signal transduction, BRAF, WNT signal transduction â-catenin.

Nuclear Regulatory Proteins: Transcriptional activators C-MYC, N-MYC, L-MYC

Cell-Cycle Regulators: Cyclins CYCLIN D, CYCLIN E, Cyclin-dependent kinase CDK4

\section{Growth factors}

Early in oral carcinogenesis TGF- á overexpressed by hyperplastic epithelium and later by inflammatory infiltrate, particularly eosinophils - surrounding the invading oral epithelium. ${ }^{2}$

Anti tumour and tumour progression role of Eosinophils: Anti tumor effect:- Eosinophils (EOS) is associated with the release of cytotoxic proteins, including eosinophil cationic protein(ECP), major basic protein (MBP), eosinophil peroxidase (EPO) and eosinophil-derived neurotoxin (EDN), which has been linked to tumour cell apoptosis. EOS is thought to be recruited to tumours, by selective EOS chemoattractant eotaxin, which binds to CCR3 receptor on these cells. ${ }^{14}$ 
Tumour progression role:- Eosinophils promote angiogenesis, release pro-angiogenic factors like basic-fibroblast growth factor (b-FGF), interleukin IL-6, IL-8, granulocyte macrophage colony stimulating factor (GM-CSF), platelet-derived growth factor (PDGF), transforming growth factor beta (TGF-â) and matrix metalloproteinase- 9 (MMP-9) on stimulation by TNF-á .

EOS can synthesise and release many others growth factors like vascular endothelial growth factors (VEGF). ${ }^{14}$

\section{Cell-surface receptors}

EGFR, the biological receptor of EGF and TGFá, is a 170,000-dalton phosphoglycoprotein frequently found to be over expressed in human oral cancers.

\section{Three mechanisms are postulated to activate the EGFR gene in carcinogenesis:}

(1) Deletions or mutations in the ligand-binding domain

(2) Over expression of the EGFR gene and

(3) Deletion in the intracellular domain of receptor ${ }^{15}$

\section{Intracellular messengers}

Of all the members of the intracellular signalling pathway, only members of the ras gene family encode for the related protein $\mathrm{P}^{21}$ localized to the cytoplasmic side of the cellular membrane. ras proteins transmit mitogenic signals by binding GTP. Hydrolysis of GTP to GDP ends the signal. ${ }^{16}$

\section{Transcription factors}

Transcription factors are proteins that regulate the expression of other genes are altered in oral cancer. Modulation of gene expression is an important outcome in the alteration of the intracellular pathways. c-myc, regulate cell proliferation and differentiation, frequently over expressed in oral cancers. cyclin DI, cell cycle promoter also amplified in head and neck Cancers. ${ }^{13}$

\section{Tumor Suppressor Genes (TSGs)}

Tumor suppressor genes or anti-oncogenes are lost due to chromosomal alterations during tumor formation. Functional loss of multiple tumor suppressor genes leads to the development of malignancy. oncogenes, effect cellular change through mutation of only one of the two gene copies. Tumor suppressor genes are inactivated by point mutations, deletions, and rearrangements in both gene copies in a "two-hit" fashion. Therefore, the loss of function of tumor suppressor genes, are difficult to achieve. The role of TGFâ in epithelial malignancy has been controversial for some time, but it is now recognized that TGF acts as a potent tumor suppressor in the early stages of tumour progression, while later functioning more to enhance the malignant phenotype. Tumour-suppressor activities have been attributed to growth inhibition and the stimulation of apoptosis. More recently, the maintenance of genomic stability and the induction of replicative senescence together with the suppression of telomerase activity have been suggested as additional tumour-suppressor effects of TGFâ. ${ }^{17,} 18$

\section{P53}

The tumour suppressor gene p53 - mutated approximately in $70 \%$ of adult solid tumours. In normal cell biology, p53 acts as a regulator of DNA synthesis. If genomic DNA damaged, p53 produced to block cell division at the GI-S boundary and stimulate DNA repair. p53 also activate apoptosis. Mutation of p53 allows tumours GI-S boundary, propagate genetic alterations which can lead to other activated oncogenes or inactivated tumor suppressor genes. Alteration of the p53 gene occurs as point mutations and deletions. ${ }^{19}$

The E 6 and $\mathrm{E} 7$ oncoproteins are normally under control of E 2 and $E 1$ inhibitory genes. These genes can be deleted or altered upon integration, leading to unchecked transcription of E6 and E7. These proteins are then able to disrupt the function of $\mathrm{Rb}$ and p53, known tumor suppressor genes. p53 has been implicated in a wide variety of cancers and is known to be the target of many different viral particles. p53 and Rb are tumor suppressor genes, they regulatecell-cyclecheckpoints at the G1 phase. If inactivated, cells are more prone to push through division and replication, even in the setting of harmful gene mutations, which can lead to malignancy. 
The $\mathrm{E} 6$ gene is able to inactivate p53 through association with $\mathrm{E} 6$ associated protein. This complex then interacts with p53 and undergoes ubiquitindependent degradation of p53. E7 is able to bind and interact with the $\mathrm{Rb}$ gene product. $\mathrm{E} 7$ has the ability to phosphorylate the $\mathrm{Rb}$ proteins, leading to degradation by ubiquitination. This subsequently leads to E 2F activation, which produces a family of transcription factors leading to cell proliferation. ${ }^{19}$

E-cadherin - cell-cell adhesion molecule associated with both invasion and metastasis, is down-regulated in oral cancers

Deleted in colon cancer (DCC) is a N-CAM-like molecule important for cell - cell contact inhibitor, mutated during oral cancer development.

Growth suppressor intracellular messengers include the adenomatous polyposis coli (APC) gene, a G like Protein frequently mutated in certain familial colorectal cancers. The transcription factor $\mathrm{Rb}$, a known tumor suppressor gene, reduced expression in a small percentage of oral tumours. Retinoic acid receptor-beta also down-regulated in head and neck cancers. ${ }^{20,21}$

\section{Conclusion}

Research on oral cancer lags behind when compared to cancer from other sites. However, efforts are intensifying through research aiming to expand the knowledge on base of human oral cancer. Hope to master all modes of investigation, which include modern molecular biology, somatic cell genetic technologies, sophisticated and novel cellculture techniques, molecular epidemiology analysis, and the treatment of oral cancer patients with biologically based therapy, including gene therapy in the next coming decades.

\section{References:}

1. Sinha R, Anderson DE, MC Donald SS, Greenwald P. Cancer risk and diet in India. J Post grad Med 2003; 4(9): 222-228.

2. Wong. Todd. Tsuji Donoff. Molecular Biology of Human Oral Cancer: CROBM 1996; 7(4):319-328.

3. MJ Mc Cullough,CS Farah. The role of alcohol in oral carcinogenesis with particular reference to alcoholcontaining mouth washes. Aus Den J 2008; 53:302-305.

4. Helmut K. Seitz, Peter Becker. Alcohol Metabolism and Cancer Risk. Alcohol Research Health 2007; 30(1):38-47.
5. Vogelstein B, Kinzler KW .The multistep nature of cancer. Trends Genet 1993; 9:138-141.

6. G. Douglas Letson. Genetic and Molecular Abnormalities in Tumours of the Bone and Soft Tissues. Cancer Control 2001; 8(3):239-245.

7. J ayanthi P Elizabeth, J oshua Ranganathan K. Agening and its implications. J OMFP 2010; 4(2): 48-51.

8. Ahsee KW, Cooke TG, Pickford IR, Soutar D, Balmain. An allel otype of squamous cell carcinoma of the head and neck using microsatellite markers. Cancer Res 1994; 54:16171621.

9. Andrew P. Feinberg. The epigenetic progenitor origin of human cancer. Nature Reviews Genetics 2006; 7: 21-37.

10. Vincent T Devita J r, Samuel Hellman, Steven R Rosen berg. Textbook of Cancer: Principles and practice of oncology. Lippincott williams and wilkins publications.

11. Robbins and Cotran. Textbook of Pathological basis of disease $7^{\text {th }}$ ed. Elsevier A division of Reed Elsevier India Private Limited.

12. Douglas Hanahan. The Hallmarks of Cancer. Cell 2000; 100:57-70.

13. Bishop J M. Molecular themes in oncogenesis. Cell 1991; 64:235 - 248.

14. Michele Conceic, Pereira A, Denise Tostes Oliveira, Luiz Paulo Kowalski. Review: The role of eosinophils and eosinophil cationic protein in oral cancer. Archives Of Oral Biology 2011; 56:353-358.

15. Hunter T. Cooperation between oncogenes. Cell 1991; 64:249-270.

16. V. Patel, C. Leethanakul, J.S. Gutkind. New approaches to the understanding of the molecular basis of oral cancer. Crit Rev Oral Biol Med 2001; 12(1):55-63.

17. Siegel PM, Massague J . Cytostatic and apoptotic actions of TGFâ in homeostasis and cancer. Nat Rev Cancer2003; 3:807-819.

18. S.S. Prime, M. Davies, M. Pring, I.C. Paterson. The role of TGFâ in epithelial malignancy and its relevance to the pathogenesis of oral cancer. Crit Rev Oral Biol Med 2004; 15(6):337-347.

19. Majid Ebrahimi, Karin Nylander, I saac van der waal. Oral lichen planus and the p53 family: What do we know? J Oral Pathol Med 2011; 40:281-285.

20. J aana Rautava, Stina Syrjanen. Human papillomavirus infections in the oral mucosa. J ADA 2011; 142(8):905-914.

21. Kim MS, Li SL, Bertolami CN, Cherrick HM, Park NH. State of p53, Rb and DCC tumor suppressor genes in human oral cancer cell lines. Anticancer Res 1993; 13:1405-1413. 